\title{
O CONCEITO DE SISTEMA NAS TEORIAS DA LINGUAGEM DA ÍNDIA ANTIGA
}

\author{
Maria Valíria Aderson de Mello Vargas \\ Universidade de São Paulo
}

\begin{abstract}
Resumo: Buscar o conceito de sistema nas teorias da linguagem da India clássica certamente implica em encontrar, na lingüistica indiana, doutrinas que testemunham um pensamento científico desenvolvido e que se aproximam das teorias da lingüística moderna. Partindo-se, aqui, da definição de Saussure de que a língua é um sistema, princípio discutido e ampliado, por exemplo, por Hjelmslev e Coseriu, é possível afirmar que, já na obra de Panini (séc. $V$ a.C.) - na qual se encontram as fontes técnicas da gramática sánscrita plenamente desenvolvidas e cujos sutra são o fundamento de vasta literatura gramatical -, a descrição que se apresenta é a de um sistema no qual os fatos $e$ os fen6menos se configuram como partes solidârias e interdependentes, em que cada elemento tem um valor por oposição a outro e, acima de tudo, de um sistema aberto a inúmeras variações.
\end{abstract}

Palavaas-chave: sistema, lingüística indiana, gramática de Panini.

Devemos, inicialmente, reconhecer que nossas considerações aqui expostas se caracterizam como um levantamento preliminar de questōes a respeito de problemas de lingüística geral e que, certamente, essas idéias serão retomadas e desenvolvidas, na medida em que se aprofundem pesquisas específicas e se concretizem projetos de estudos sobre as teorias da linguagem na India antiga.

Como nos propusemos buscar o conceito de sistema naquelas teorias, julgamos conveniente partir das idéias de Saussure, reunidas por Bally e Sechehaye no Curso de Lingïlstica Geral, segundo as quais a linguagem, em qualquer momento de sua existência, deve apresentar-se como uma organização, como sistema. E, mais, que as operaçōes necessárias à determinação duma unidade pressupōem que esta unidade se relaciona com as outras e se reintegra no interior de uma operação de conjunto. Também, que pela noção de sistema concebem-se as partes da língua como sincronicamente solidárias e interdependentes - cada elemento tem um valor determinado por oposição a outro.

A língua é, pois, concebida como um "sistema de sinais", constituído por unidades oponentes entre si. Vale lembrar, ainda, as idéias de Saussure a respeito do circuito da fala, ao qual, segundo ele, cumpre acrescentar uma faculdade de associação e de coordenação, que se manifesta por não se tratar mais de sinais isolados, faculdade, enfim, que desempenha o principal papel na organização da língua enquanto sistema. E, como lembra Maria Luísa F. Miazzi (Miazzi, 1972, p. 89), a aplicação do conceito básico de "sistema" e de "oposição" dos elementos lingǘrsticos, que, no campo dos seres humanos, produzem fecundamente a 
fonologia, estende-se à morfologia e à sintaxe, assim como ao estudo do léxico (semântica estrutural).

Buscando aproximar, então, as concepções das modernas teorias lingüisticas das teorias da linguagem da Índia antiga, chama-nos primeiramente a atenção aquela definição de língua enquanto sistema cujas partes constituintes são sincronicamente solidárias e interdependentes e facilmente se relaciona essa idéia, por exemplo, à do gramático indiano Bhartrhari (séc. VII d. C.), para quem o sentido da frase consiste na pratibha, que se define como uma inter-relação indivisivel de palavras. A questão de saber se a frase corresponde a uma realidade exterior ou se ela consiste, ao contrário, numa relação indivisivel de palavras foi amplamente discutida pelos filósofos da linguagem indianos. É interessante, nesse sentido, acompanhar estudos como os de Ruegg que contrapõe essas idéias dos gramáticos filósofos indianos às concepçōes dos lingüistas modernos. Estes, conforme Ruegg (Ruegg, 1959, p. 88), estabelecem distinções entre a semântica - cujo objeto são as relações associativas do significado e do significante e que trata assim das coisas denominadas - e a sintaxe, que tem por objeto uma significação de natureza puramente relacional ou sintagmática e trata unicamente da ordem dos signos.

Mas, examinando-se mais de perto o trabalho dos gramáticos indianos, convém ressaltar que as descrições de Panini, na sua famosa Astadhỷayi, baseadas no método da conexão e da diferença denominada anvayavyátireka, apontam claramente para os usos e não se restringem, pois, à descrição lingüistica da norma, culta ou não. Por exemplo, na distinção entre o tema e o sufixo aquele método é essencial, pois, por meio dele, uma base nominal como vrksa, "árvore", distingue-se dos sufixos casuais nas palavras vrksas, vrksau, vrkse, etc. Tal método é também responsável pela gama de verdadeiros tratados de interpretação da obra de Panini, 0 que vem, na verdade, demonstrar que o que Panini descreve não é um sistema "fechado", "imutável", mas que o objeto descrito é altamente "motivado", "vivo", aberto a inúmeras variações.

Cabe lembrar, nesse ponto, Katyayana (séc. III a. C.) e Patañjali (séc. I a. C.), representantes da primeira fase dos estudos paninianos, de acordo com a classificação de Dvivedi (Dvivedi, 1978). Para aqueles teóricos, o objeto da gramática se situa em explicar o uso corrente entre os falantes de uma língua e não é prescritivo, o que se infere, por exemplo, da impossibilidade de completar-se um elenco de temas nominais. Nesse sentido, lembramos as duas direções principais que Panini tomou para arranjar seus sutra: utsarga (regra geral) e apavada (outras possibilidades de uso).

Não é difícil compreender, pois, o fato de obras como os pratiçakhya, sobretudo o Rkpratiçakhya e o Atharvapratiçakhaya, se bem que consagrados em princípio à descrição fonética dos samhita correspondentes, Rgveda e Atharvaveda, respectivamente, ultrapassarem, por vezes, esses limites e compreenderem matérias gramaticais em geral sob influência da obra de Panini, como entende Ruegg (Ruegg, 1959, p. 30); isso vem confirmar que a preocupação de Panini se concentrava essencialmente no uso. Assim, convém compreender o método de sua obra como descritivo, que tem, como base de uma grande parte de sua descrição, a raiz (dhatoh. 3.1.91 - sutra que vai reger os 540 seguintes), e que também aponta 0 uso de pessoas cultas (çistacara) e que menciona fatos védicos sobretudo afim de situar a bhasa, a "línguagem corrente" em relação ao uso mais antigo. 
Também confirma essa tendência de situar-se no uso o fato de autores de época posterior utilizarem-se, para explicar os enunciados de Panini, de procedimentos como o da phakkika (argumentação ou tese a ser mantida) e também estenderem sua abordagem de modo a recobrir os usos que só aparecem depois de Panini, ao curso da evolução subseqüente da língua sânscrita. Assim, convém lembrar que as regras de interpretação (paribhasa) revelam também essa intenção, embora não seja essa sua função principal.

Comentadores a partir de Katyayana e Patañjali, estes aqui já citados, distinguem na Astadhyayi de Panini uma doutrina de lingülstica geral elaborada; uma descrição tal de uma língua pressupõe em grande medida uma teoria lingülstica desenvolvida. A forma dos sutra demonstra que a ciência gramatical atingira um nível elevado de desenvolvimento e a estrutura interna na obra de Panini - com suas regras governantes (adhikara), o princípio da recorrência (anuvrtti), a doutrina do purvatrasiddam (o que previamente não existia ou não teve efeito), enfim, o já mencionado método de conexão e diferença e o recurso a regras interpretativas serviu para apoiar as doutrinas e os argumentos filosóficos de escolas diferentes.

E fundamental, entretanto, discutir a idéia de Hjelmslev de que a todo processo corresponde um sistema que permite auxiliá-lo e descrevê-lo por meio de um número restrito de premissas. 0 objetivo da teoria da linguagem, como afirma Hjelmslev (Hjelmslev, 1975, p. 8), situa-se em verificar a tese da existência de um sistema subjacente ao processo (composto por um número limitado de elementos que constantemente reaparecem em novas combinações) e a tese de uma constância que subentende flutuaçōes, e aplicar esse sistema a um objeto que parece prestar-se a isso de modo particular.

Assim, deve-se lembrar aqui o nível da fala (ou terceiro nível, ou grau, acrescido por Coseriu à hierarquia nocional, sistema-norma-uso, proposta por Hjelmslev), onde é necessário colocar todas as variações que 0 falante pode acrescentar à estruturação social. Reforçam essa idéia as afirmações de Meillet (Meillet, 1938, p. 72), para quem uma lingua é um sistema rigorosamente coeso de meios de expressão comuns a um conjunto de falantes; não existe fora dos indivíduos que falam (ou que escrevem) a língua; não obstante, existe independentemente de cada um deles.

É preciso, pois, ir além das teorias saussureanas para, com Hjelmslev (Hjelmslev, 1975, p. 49), lembrar que a finalidade por nós atribuída às línguas faz delas sistemas de signos, mas, conforme sua estrutura interna, elas são sobretudo sistemas de figuras que podem servir para formar signos (e novos signos, novas palavras, novas raizes).

A respeito das combinações possiveis no sistema, voltando aos teóricos indianos, devemos, com Ruegg (Ruegg, 1959, p. 27), por exemplo, lembrar a importância capital do fenômeno denominado vakyaniyama, ou "determinação do vakya (discurso, asserção, fala)", no mantra (invocaçōes utilizadas nos rituais), pois fixa a forma dessas invocações e torna impossivel a transferência gramatical e lexical (uha) pelas mudanças de posiçăo e pelas substituições de palavras segundo o sentido que se queira exprimir. Assim, o mantra adquire um valor ritual em razão dessa sua forma determinada. A esse respeito, Bhartrhari, na obra Vakyapadiya 2.259 ,como lembra Ruegg (Ruegg, 1927, p. 27), ressalta que para os gabdabhedavadin (aqueles que admitem que a palavra é mutável e que um mantra pode então revestir-se de formas diferentes segundo o contexto ritual) o mantra é 
diferente segundo sua aplicação ritual (viniyoga), bem como ele pode sofrer uma mudança pelo fenômeno denominado uha. Assim, o sentido de uma fórmula no mantrapatha (recitação do mantra), sem aplicação ritual, corresponde ao sentido "formal" (svarupartha), enquanto que esse mantra, numa conexão particular, possui seu valor pleno determinado pelo contexto ritual. Desse modo, uma fórmula aparentemente idêntica possui, na verdade, valores diferentes nas combinações diversas.

$E$, ainda, outro exemplo de que era comprovada, nas teorias da linguagem da India antiga, a variabilidade do sistema é a questão de saber se uma palavra se refere à espécie (akrti) ou ao indivíduo (dravya). Para isso, recorremos a Panini que ensina, ao menos, duas possibilidades: o sutra 1.2.58, jatyakhyayam ekasmin bahuvacanam, prevê que "o plural (bahuvacanam) é opcionalmente usado no sentido do singular (ekasmin) quando designa espécies (jatyakhyayam)", enquanto que 0 sutra 1.2.64 sarupanan ekaçesa ekavibhaktau, descreve: "quando há ocorrência única de uma terminação no singular (ekavibhaktau), apenas um de uma série de temas mórficos repetidos (sarupanam) permanece em uso (ekaçesah)". Entre os comentadores, como aponta Ruegg (Ruegg, 1959, p. 32), Patañjali, em sua obra Mahabhasya, informa que Panini se refere, no primeiro caso, à espécie e, no segundo, ao indivíduo. De acordo com outros, como Vyadi, Panini se refere, nos dois casos, ao indivíduo. Segundo a interpretação dos gramáticos ulteriores, a palavra se refere ao indivíduo qualificado pelo universal, como é exemplo a expressão jativiçistavyakti, de Nagesa, em sua obra Man̂jusa (séc. XVIII).

Para concluir, por enquanto, esta série de considerações, reformulemos, com Coseriu (Coseriu, 1979, p. 215), a idéia de Saussure para quem o sistema é, no fundo, um estado, e o estado é, de alguma maneira, estável. Devemos afirmar, sim, que um sistema lingüistico em seu uso é sempre sincrônico em dois sentidos: no sentido de que, a todo instante, cada um dos seus elementos está em relação com outros, e no sentido de que o próprio sistema está sincronizado com seus usuários, razão por que não é estático e sim dinâmico. Ademais, como infere Coseriu, apesar do aparente paradoxo, a estaticidade não é um fato sincrônico, mas diacrônico: para comprová-lo é necessário mover-se na linha do tempo.

Abstracr: Searching the system concept in the language theories from classic India certainly implicates in finding, in the Indian linguistics, doctrines which testify a developed scientific thought and that approach the modern linguistic theories. Therefore, coming from Saussure's definition that the language is a system, a discussed and enlarged principle, for instance, by Hjelmslev and Coseriu, it is possible to affirm that even in Panini's work N B. C.) - in which the technical sources of the fully developed Sanskrit grammar are found, and whose sutra are the foundations of a vast grammatical literature - the description that is presented is the one of a system in which the facts and the phenomena are configurated as interdependent and solidary parts, in which each element has a determined value in opposition to another, but, above all, of a system that is opened to numberless variations. 
Bibliografia

COSERIU, E. Sincronia, diacronia e história. Trad. Carlos Alberto da Fonseca e Mário Ferreira. Rio de Janeiro/São Paulo: Perspectiva/EDUSP, 1979.

DVIVEDI, H. P. Studies in Panini. Delhi: Inter-India Publications, 1978.

HJELMSLEV, L. Prolegômenos a uma teoria da linguagem. Trad. J. Teixeira Coelho Neto. São Paulo: Perspectiva, 1975.

MEILLET, A. Linguistique historique et linguistique générale, II. Paris: Librairie C. Klincksieck, 1938.

MIAZzı, M. L. F. Conceitos básicos de Saussure. In: Introdução à lingüistica românica. São Paulo: Cultrix, EDUSP, 1972, cap. VII.

PANINI. Astadhyayi. Trad. Sumitra M. Katre. Delhi: Motilal Banarsidass, 1989.

RUEGG, D. S. Contributions à l'histoire de la philosophie linguistique. Paris: Ed. de Boccard, 1959.

SAUSSURE, F. de. Curso de Lingürstica Geral: Org. Charles Bally e Albert Sechehaye. Trad. Antônio Chelini, José Paulo Paes e Izidoro Blikstein. São Paulo: Cultrix, 1970, 2a. ed. 